\title{
THE HISTORY OF BILINGUAL DICTIONARIES RECONSIDERED: AN ANCIENT FRAGMENT RELATED TO PS.-PHILOXENUS (P.VARS. 6) AND ITS SIGNIFICANCE
}

\begin{abstract}
This article identifies a papyrus in Warsaw, P.Vars. 6, as a fragment of the large LatinGreek glossary known as Ps.-Philoxenus. That glossary, published in volume II of G. Goetz's Corpus Glossariorum Latinorum on the basis of a ninth-century manuscript, is by far the most important of the bilingual glossaries surviving from antiquity, being derived from lost works of Roman scholarship and preserving valuable information about rare and archaic Latin words. It has long been considered a product of the sixth century A.D., but the papyrus dates to c.200, and internal evidence indicates that the glossary itself must be substantially older than that copy. The Ps.-Philoxenus glossary is therefore not a creation of Late Antiquity but of the Early Empire or perhaps even the Republic. Large bilingual glossaries in alphabetical order must have existed far earlier than has hitherto been believed.
\end{abstract}

Keywords: papyri; dictionaries; glossaries; bilingual; Philoxenus; Cyrillus; Latin; Warsaw

Bilingual dictionaries have long been a vital tool for understanding and using foreign languages. ${ }^{1}$ Whether pocket-sized or multi-volume, whether on paper, on screen or on papyrus, dictionaries are essential to language learners and scholars today and have been for thousands of years. But what were ancient bilingual dictionaries actually like? When Romans encountered an unfamiliar Greek word, or Greeks an unfamiliar Latin word, what kind of resource did they reach for, and how likely was it to contain the word they sought? Until recently a clear answer to that question was available, but the discovery of a new dictionary fragment on papyrus throws the current understanding into doubt.

Like other types of ancient literature, ancient bilingual dictionaries survive in two forms: as (largely) intact works via the medieval tradition and as small fragments of ancient copies. The dictionaries preserved in medieval manuscripts include two large works, the Latin-Greek glossary of Ps.-Philoxenus with c.11,000 entries and the Greek-Latin glossary of Ps.-Cyrillus with c.15,000 entries, as well as many

\footnotetext{
${ }^{1}$ I am grateful to Constantinos Balamoshev for allowing me to see the original papyrus and for help with reading it, to Philomen Probert and Daniela Colomo for help with this article, to Marco Fressura for allowing me to use his work before publication and to Maria Chiara Scappaticcio for encouraging me to re-edit this papyrus as part of the PLATINUM project and therefore prompting this discovery. The research leading to these results received funding from the European Research Council under the European Union's Horizon 2020 research and innovation program (Grant agreement no. 636983); ERC-PLATINUM project, University of Naples 'Federico II'.
} 
smaller glossaries. ${ }^{2}$ Both from internal evidence and from comparison with the ancient fragments, it had long seemed clear that some of the small glossaries were old and represented the only types of dictionaries in use for most of antiquity: Latin and Greek speakers using each other's languages would have relied on little glossaries containing at most a few thousand words, not normally arranged in alphabetical order. Only in Late Antiquity did large dictionaries in alphabetical order come into use, with the creation of the ancestors of Ps.-Philoxenus, Ps.-Cyrillus and other dictionaries/glossaries now lost. It ought not to be possible to find an early papyrus fragment closely related to Ps.-Philoxenus-but that is what has turned up.

\section{PS.-PHILOXENUS' GLOSSARY}

Ps.-Philoxenus ${ }^{3}$ is hardly a household name, but his work is of great importance for our understanding of ancient vocabulary, since it preserves numerous rare and archaic words with their explanations. To quote Gustav Loewe, 'The work falsely attributed to Philoxenus is beyond doubt the best and as it were the most learned of all the bilingual glossaries that exist.' ${ }^{4}$ As often in the case of ancient glossaries, the interpretations of many readings are doubtful, and therefore the best edition of Ps.-Philoxenus prints not a corrected text but a transcript of the manuscript, with corrections in a separate volume. ${ }^{5}$ The extracts below, which present the transcript on the left and modern interpretations on the right, give a sense of what the glossary is like: ${ }^{6}$

\footnotetext{
${ }^{2}$ Most of these are published in the Corpus Glossariorum Latinorum (henceforth $C G L$ ): the second volume (CGL II = Glossae Latinograecae et Graecolatinae, edited by G. Goetz and G. Gundermann [Leipzig, 1888]) contains Ps.-Philoxenus (pages 1-212), Ps.-Cyrillus (pages 213-483) and many of the minor glossaries (pages 485-597). The third volume (CGL III =Hermeneumata Pseudodositheana, edited by G. Goetz [Leipzig, 1892]) contains the Hermeneumata, a huge collection of glossaries that individually are fairly short. Ps.-Philoxenus has also been edited by M. Laistner as part of W.M. Lindsay's Glossaria Latina collection (vol. II [Paris, 1926], 123-291); for some of the reasons why CGL remains the standard edition, see G. Goetz's review of this volume in Gnomon 2 (1926), 597-605. Some of the Hermeneumata glossaries also have other editions, and some have never been edited at all: E. Dickey, The Colloquia of the Hermeneumata Pseudodositheana I (Cambridge, 2012), 17-20. Because the only practical way to find general information about attestation in the glossaries as a group is to use the corrected indices in CGL volumes VI and VII (Thesaurus glossarum emendatarum, edited by G. Goetz [Leipzig, 1899-1901]), I have done so, and therefore throughout this article generalizations about such attestation do not take into account material not in $C G L$.

${ }^{3}$ The Philoxenus to whom this glossary was once attributed is not the grammarian of the first century B.C. but Flavius Theodorus Philoxenus, consul in A.D. 525; the misattribution was based on a Renaissance confusion about the location of an ascription to him. No such ascription appears in the main manuscript of the glossary, the ninth-century Parisinus lat. 7651 (Regius 5479). See G. Goetz, 'Glossographie', in G. Wissowa and W. Kroll (edd.), Pauly's Real-Encyclopädie der classischen Altertumswissenschaft VII.1 (Stuttgart, 1910), 1433-66, at 1439.

4 'Glossariorum bilinguium quotquot exstant omnium procul dubio optimum et ut ita dicam doctissimum illud est cui Philoxeni nomen falso inscribitur' (G. Loewe, Prodromus corporis glossariorum Latinorum [Leipzig, 1876], 180).

${ }_{5}$ That is, uncorrected transcripts are normally given in CGL II-V, but in the Thesaurus (CGL VIVII) Goetz listed all the words and forms that he thought occurred in the glossaries, with references to the pages and lines on which they occurred. For an insightful and sympathetic study of Goetz's editing system, see A.C. Dionisotti, 'On the nature and transmission of Latin glossaries', in J. Hamesse (ed.), Les manuscrits des lexiques et glossaires de l'antiquité tardive à la fin du moyen âge (Louvain-la-neuve, 1996), 205-52.

${ }^{6}$ The first extract is CGL II 56.29-46 in Goetz's edition (n. 2) and DU 35-52 (page 177) in Laistner's (n. 2); the second is CGL II 42.2-14 in Goetz's edition and DE 244-56 (page 167) in
} 


\subsection{Sample extracts}

Dubingeniosus $\alpha \varphi v \eta s$

Ducitur $\alpha \gamma \varepsilon \tau \alpha l^{\circ} \varepsilon \lambda \kappa \varepsilon \tau \alpha l$

Ductile $\varepsilon \lambda \kappa v \sigma \tau o v$

Ducimus $v \pi \varepsilon \imath \lambda \eta \dot{\eta} \varphi \alpha \mu \varepsilon v$

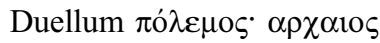

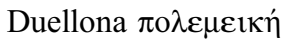

Dúint $\delta o i ́ \varepsilon v \delta \omega \sigma \omega \sigma ı v$

Duit doín

Dulce $\gamma \lambda \cup \kappa v$

Dulcior $\gamma \lambda \cup \kappa v \tau \varepsilon \rho \varsigma$

Dulcium $\pi \lambda \alpha \kappa o v \vee \tau \alpha$

Dulcissimus $\gamma \lambda v \kappa v \tau \alpha \tau \sigma \varsigma$

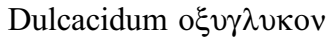

Ducale $\alpha \gamma \omega \gamma \varepsilon v \sigma o \tau \omega v^{*} \kappa \tau \eta \nu o v$

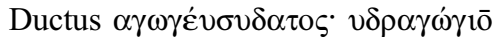

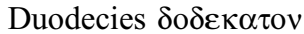

Duae $\alpha$ idvo

Duas $\tau \alpha \varsigma \delta$ ขo

Deliquit liquefecit $\eta \mu \alpha \rho \tau \varepsilon v$

Deliquium solis $\varepsilon \kappa \lambda \eta \psi \wedge \varsigma \eta \lambda$ เov

Delfinus $\delta \varepsilon \lambda \varphi i v$

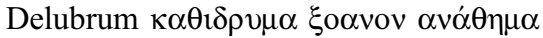

Deliberandi $\tau 0 v \sigma \kappa \varepsilon \pi \tau \varepsilon \sigma \theta \alpha \imath$

Delegauit $\alpha \varphi \omega ́ \rho ı \varepsilon v$

Delatio $\alpha v \alpha \varphi \rho \rho \alpha ́$

$\mathrm{Lib}_{7}$ de offo pro consulis

Delitum $\alpha \pi \circ \gamma \alpha \lambda \alpha \kappa \tau 1 \sigma \theta \varepsilon v$

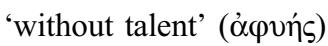

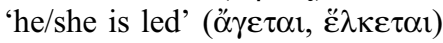

'movable', neuter ( $\dot{\varepsilon} \lambda \kappa v \sigma \tau o ́ v)$

'we consider' (i $\pi \varepsilon \imath \lambda \eta \dot{\eta} \varphi \alpha \mu \varepsilon v$ 'we have understood')

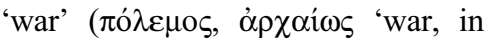
archaic language')

'Bellona' ( $\pi \mathrm{o} \lambda \varepsilon \mu \mathrm{i} \eta \dot{~ '[g o d d e s s] ~ o f ~}$ war')

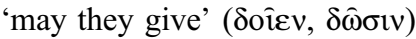

'may he/she give'

'sweet', neuter ( $\gamma \lambda v \kappa v ́)$

'sweeter' ( $\gamma \lambda v \kappa v ́ \tau \varepsilon \rho \varsigma)$

'cake', accusative $(\pi \lambda \alpha \kappa o v v \tau \tau)$

'sweetest' ( $\gamma \lambda \nu \kappa v ́ \tau \alpha \tau \mathrm{s})$

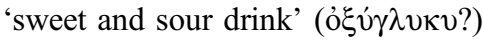

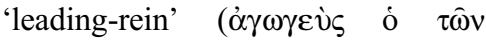
$\kappa \tau \eta \nu \hat{\omega} v$ 'leading-rein of animals')

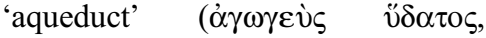

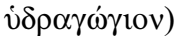

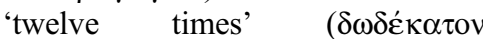
'twelfth'); there is a variant read-

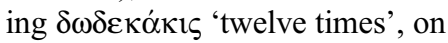
which Goetz comments 'quo non opus'

'two', feminine nominative plural

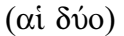

'two', feminine accusative plural

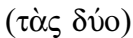

'he/she dissolved' (delicuit from deliquesco and/or delīquit from

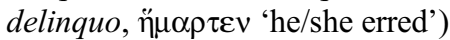

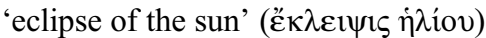
'dolphin' (delphinus, $\delta \varepsilon \lambda$ pív)

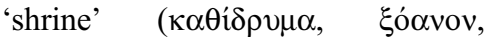
óvó $\theta \eta \mu \alpha \quad$ 'shrine, image, offering')

'of considering' (

'he/she delegated' (’’ $\varphi \omega ́ \rho ı \varepsilon \varepsilon)$

'denunciation' ('ò $\alpha \varphi \circ \rho \alpha ́)$

(the source of this word is the) Liber de officio proconsulis

'weaned', neuter (delicum, фं

Laistner's. In the right-hand column the corrected forms of both Latin and Greek words (and hence the interpretations) come from Goetz's Thesaurus, but the translations are mine; translations and grammatical information apply to both Latin and Greek unless specified otherwise. 
Delituit $\dot{\varepsilon} \lambda \alpha \theta \varepsilon v$

Deliberauite $\delta\llcorner\alpha \sigma \kappa \varepsilon \psi \alpha \sigma \theta \alpha \imath$

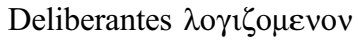

Delinquere $\alpha \mu \alpha \rho \tau \alpha \dot{v} \varepsilon \varepsilon v$

Deliciae $\sigma \pi \alpha \tau \alpha \dot{\lambda} \alpha \mathrm{l}$ 'he/she hid' ('̌ $\lambda \alpha \theta \varepsilon v$ )

'to have considered' (deliberauisse, $\delta 1 \alpha \sigma \kappa \varepsilon ́ \psi \alpha \sigma \theta \alpha \mathrm{l})$

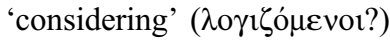

'to fail' ( $\alpha \mu \alpha \rho \tau \alpha \dot{\alpha} \varepsilon i v)$

'delight' ( $\sigma \pi \alpha \tau \alpha \dot{\alpha} \lambda \alpha \mathrm{l}$ 'luxuries')

These extracts illustrate many of the main characteristics of Ps.-Philoxenus: inclusion of rare words (dubingeniosus occurs only here, and delicus, dulcium and ducale are rare), ${ }^{7}$ correct interpretation of archaic forms (even many native Latin speakers of Cicero's day would have had trouble explaining duint and duit), accurate information on usage (duellum was indeed archaic language), occasional citation of sources (both mainstream authors like Horace and obscure ones: the Liber de officio proconsulis cited here is known only from references in Ps.-Philoxenus ${ }^{8}$ ), alphabetization by two or three letters only and a mixture of inflected forms with what we would think of as citation forms. Sometimes a single Latin word is given several Greek equivalents, either synonyms (as with ductus) or different from each other (as with duint); on the other hand, where there are two Latin words they are not necessarily both equivalents of the Greek word (as with deliquit, where both liquefecit and $\eta_{\mu \alpha \rho \tau o v}$ appear to be glosses of deliquit, on which they offer different interpretations). The two languages normally match in form as well as in meaning and, when Greek words are ambiguous, articles may be added to make the form of the Latin clear (as with duae and duas). But the matches are not always exact and sometimes seem to represent the equivalent that might appear in a particular context rather than a literal translation of the lemma in isolation (as when the present ducimus is glossed with the perfect $\dot{\tau} \pi \varepsilon \imath \lambda \dot{\eta} \varphi \alpha \mu \varepsilon v$ ).

\subsection{Sources}

Where does the information in this glossary come from? Scholars have devoted considerable energy to answering this question. ${ }^{9}$ The ultimate sources of many entries are clearly literary texts; literary sources are particularly likely for inflected forms such as delituit and duint, but citation forms can also appear in literary texts, as dulcior does at Verg. Ecl. 7.37. In Laistner's edition of Ps.-Philoxenus delituit is marked as derived from Verg. G. 3.417, duint as derived from Cic. Cat. 1.22 and dulcior as perhaps derived from the Eclogues passage. ${ }^{10}$ At first glance such attributions seem arbitrary: all these forms are also found in numerous other passages, ${ }^{11}$ and moreover dulcior in

\footnotetext{
7 See $T L L$ s.vv.

8 That is, this title occurs only in Ps.-Philoxenus; fragments found in other sources may belong to the same work, which in the nineteenth century was somewhat speculatively reconstructed as a tenbook work by the second/third century jurist Ulpian (H. Rudorff, 'Über den Liber de officio proconsulis', Philologische und historische Abhandlungen der königlichen Akademie der Wissenschaften zu Berlin [1865], 233-321). Some other scholars think it was a bilingual legal glossary; see the reference to it as 'this Viceroy's Conversation-manual' in W.M. Lindsay, 'The Philoxenus glossary', $C R 31$ (1917), 158-63, at 161 .

9 See Loewe (n. 4), 186-9; A. Dammann, De Festo Pseudo-Philoxeni auctore (Commentationes Philologae Ienenses V) (Diss., Leipzig, 1892); Goetz (n. 3), 1439; Lindsay (n. 8), 161-2; G. Goetz, De glossariorum Latinorum origine et fatis (= CGL I) (Leipzig, 1923), 23-34; Laistner (n. 2), 130-5; Goetz (n. 2 [1926]), 601-2; also earlier discussions cited in these works.

${ }^{10}$ Laistner (n. 2), DE 251, DU 41, DU 44.

${ }^{11}$ E.g. delituit in Plaut. Rud. 465; Cic. Phil. 2.77, Red. sen. 3; Livy 38.46.7, 45.6.6; Sen. QNat. 6.3.3, 7.30.4; Ov. Met. 4.337; Columella, Rust. 7.4; duint four times each in Plautus and Terence,
} 
the Eclogues passage should be feminine, not masculine as Ps.-Philoxenus' gloss indicates. But there is a reason for the choice of these particular passages: words found in Cicero's Catilinarians and in Virgil appear far more frequently in Ps.-Philoxenus than words found in most other texts, and a number of entries preserve explicit references to Virgil, so it is thought that the compiler of the glossary used those texts as sources. ${ }^{12}$ Hence a word found both in Plautus and in one of the Catilinarians probably comes from Cicero, but one found both in Virgil and in a work of Cicero other than the Catilinarians probably comes from Virgil. The reason the masculine form of the Greek equivalent of dulcior is not counter-evidence for Virgilian provenance is that scholars envision the initial collection and glossing to have been a Latin-Latin process, with Greek glosses later substituted for the Latin ones or simply added to them (as with deliquit above); any Latin gloss for dulcior would probably have been ambiguous as to gender and therefore would probably have been translated into Greek with a masculine. Indeed a few entries in Ps.-Philoxenus are still Latin-Latin, for example deterreret detraheret ${ }^{13}$ since the Latin-Latin entries are often taken from Horace, ${ }^{14}$ the source of this entry could be the occurrence of deterreret at Sat. 1.4.112.

But not all entries were taken directly from literature. The Liber de officio proconsulis cited in one of the extracts above may have been a legal glossary, and many entries are thought to come from a Latin-Latin lexicon entitled De uerborum significatu, originally composed in the Augustan period by Marcus Verrius Flaccus and epitomized (probably in the second century A.D.) by Sextus Pompeius Festus. An explicit reference to Festus is probably concealed in the entry Adoriosus $\varepsilon v \delta o \xi_{0}$.

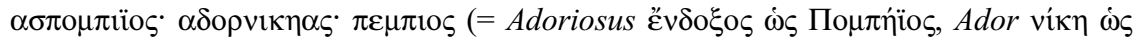
По $\mu \pi$ íios). ${ }^{15}$ Verrius Flaccus' version of this lexicon is lost, and only about a third of Festus' version survives, meaning that for most of the lexicon we have only a further epitome made in the eighth century by Paul the Deacon. Despite this drawback it is notable that many of the lemmata in Festus/Paul also appear in Ps.-Philoxenus, often with glosses that could be derived from the longer, Latin explanations given by Festus/Paul. ${ }^{16}$

In the modern world Latin-English and English-Latin dictionaries tend to contain largely the same words; the difference is primarily one of organization. We might therefore expect Ps.-Philoxenus to contain mostly the same words as the large Greek-Latin dictionary, Ps.-Cyrillus, but this is not the case: only a minority of the words in each lexicon are found in both. For example, Ps.-Philoxenus includes 1,011 ${ }^{17}$ Latin words beginning with $D$ - and Ps.-Cyrillus 978, but only 238 of those words occur in both

also Cic. Phil. 10.13; dulcior in Plaut. As. 614; Hor. Sat. 2.4.15; Prop. 3.8.29; eleven times in Cicero, four times in Ovid, etc.

12 Goetz (n. 9 [1923]), 31-2; Laistner (n. 2), 133-5; Lindsay (n. 8), 161.

${ }^{13}$ CGL II (n. 2), 47.26.

14 Dammann (n. 9), 17-25; Goetz (n. 9 [1923]), 25-7; Lindsay (n. 8), 161.

${ }^{15} C G L$ II (n. 2), 8.21; for the interpretation, which goes back to Scaliger, see Dammann (n. 9), 26 and CGL I 27 s.vv. ador, adoriosus.

${ }^{16}$ See Dammann (n. 9), 26-47; Goetz (n. 9 [1923]), 28-31; Laistner (n. 2), 130-1; Lindsay (n. 8), 162; A.C. Dionisotti, 'Greek grammars and dictionaries in Carolingian Europe', in M.W. Herren (ed.), The Sacred Nectar of the Greeks (London, 1988), 1-56, at 6.

17 This is not the number of entries in the $D$ - section of Ps.-Philoxenus (that figure would be 1,194, because some words appear more than once: see next section), but the number of Latin words in the $D$ - section of the Thesaurus in CGL VI (n. 5 above) that contain references to Ps.-Philoxenus. As Ps.-Cyrillus is alphabetized by the Greek and therefore has no $D$ - section, only by using the Thesaurus can one obtain strictly comparable results for both works. 
dictionaries, and only 186 occur in both with the same Greek equivalents. ${ }^{18}$ This difference is part of a larger pattern: ancient bilingual glossaries do not typically share many entries with each other, unless they are historically related. Thus of the 2,110 Latin words beginning with $D$ - that appear in ancient bilingual glossaries, only 21 per cent occur in more than one glossary; the remaining 79 per cent include 33 per cent occurring only in Ps.-Philoxenus, 29 per cent only in Ps.-Cyrillus and 15 per cent only in the Hermeneumata glossaries. ${ }^{19}$

Broadly speaking, Ps.-Cyrillus has more everyday vocabulary and Ps.-Philoxenus more obscure and archaic terminology. The two seem to be different selections of the Latin vocabulary, made with different goals in mind. ${ }^{20}$ Yet some of the shared glosses are nevertheless identical, and in a few cases it is unlikely that these agreements could have come about otherwise than from a shared source. ${ }^{21}$ Therefore, it is generally agreed that both glossaries drew from a lost work that contained the shared material; this work must have been a bilingual glossary, since both lemmata and glosses match in the shared entries that survive.

\subsection{Composition process and dating}

The discovery of this shared source led scholars to ask whether it might have been the source of more than just the entries now shared between Ps.-Philoxenus and Ps.-Cyrillus. After all, if the compilers of one or both glossaries had taken more entries from the shared source, we would not be able to identify those entries by comparing the two surviving glossaries. In the end, scholars concluded that more entries had indeed been taken, and in fact that the shared source had probably been an enormous protoglossary that contained all or most of the material now found in Ps.-Philoxenus as well as all or most of the material now in Ps.-Cyrillus: the two extant glossaries were thought to be simply (or at least mostly) extracts from the proto-glossary, with their different characteristics arising from the different selections made by their compilers. ${ }^{22}$ According to this theory, the other sources of Ps.-Philoxenus were actually sources of the proto-glossary. The proto-glossary was argued to have been in the order Latin-

\footnotetext{
18 I.e. more or less the same Greek word appears as a gloss for more or less the same Latin wordbut even then the entries in one or both dictionaries often also contain other glosses that do not match.

${ }^{19}$ These figures come from the $D$ - section of the Thesaurus in CGL VI (n. 5 above). For the purpose of these calculations I treat as separate words anything that is listed there as a separate word: every inflected form of a noun or verb is counted separately (contrary to the usual practice today, but in keeping with the ancient practice), and so are identical forms that belong to different parts of speech. Occurrences in the Latin-Latin glossaries are ignored. The resulting sample contains 2,110 Latin words, of which 442 occur in more than one glossary, 694 occur only in Ps.-Philoxenus, 620 occur only in Ps.-Cyrillus and 322 occur only in Hermeneumata glossaries. The Hermeneumata glossaries are treated as a single glossary here because they are historically related.

${ }^{20}$ Although it cannot be completely ruled out that one of the sources was a work about Greek and therefore made a selection from the Greek vocabulary, scholars have always agreed that Ps.-Philoxenus is fundamentally a work about Latin, not about Greek. All the literary sources involved seem to be Latin ones, and Festus was a work about Latin.

${ }^{21}$ E.g. deuehitur $\kappa \alpha \tau \alpha \pi \lambda \varepsilon \varepsilon \dot{~ i n ~ P s .-P h i l o x e n u s ~(C G L ~ I I ~ 47.35) ~ a n d ~ \kappa \alpha \tau \alpha \pi \lambda \varepsilon 1 ~ d e u e h i t u r ~ i n ~}$

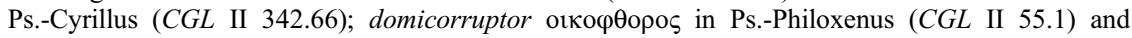

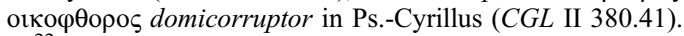

22 Goetz (n. 9 [1923]), 33; Laistner (n. 2), 125-6; cf. W.M. Lindsay, 'The Affatim glossary and others', $C Q 11$ (1917), 185-200, at 200.
} 
Greek, like Ps.-Philoxenus, since some of the Greek-Latin entries in Ps.-Cyrillus look like originally Latin-Greek entries that have been inverted. ${ }^{23}$

Thus far both editors of Ps.-Philoxenus agreed, but they disagreed about the composition process of the proto-glossary. Goetz envisioned a gradual accretion of numerous different sources; in this he followed Loewe, Dammann and Rudorff, who had developed this theory as the composition process for Ps.-Philoxenus' glossary itself before the idea of the proto-glossary was suggested. ${ }^{24}$ Lindsay and Laistner, however, saw a simpler two-step process taking place over a short period: first, the compilation of the proto-glossary directly from sources available to its creator (not via earlier glossaries), and then the excerpting and partial rearrangement of the material now in Ps.-Philoxenus and Ps.-Cyrillus. ${ }^{25}$ The nature of the composition process matters because Ps.-Philoxenus contains material from lost sources such as Festus: if Lindsay and Laistner were right about the simplicity of the composition process, modern scholars may be able to disentangle it and restore earlier phases of the glossary tradition, including the lost sources. If Goetz and Loewe were right, however, the glossaries have a history too long and too complex to make such restorations successful.

These differences affected how scholars approached specific problems in the text. For example, about six hundred of the entries in Ps.-Philoxenus occur twice, either in exactly the same form or in closely related forms where one is likely to be a corruption of the other. Loewe and Goetz thought that this situation arose from the compiler's use of two historically related sources, both of which contained the entries that appear twice. ${ }^{26}$ Lindsay and Laistner, on the other hand, thought that most of the double entries were deliberate cross-references, accidental repetitions or cases where a scribe added a corrected entry but failed to delete the original incorrect one. ${ }^{27}$

Both the proto-glossary and the extant Ps.-Philoxenus and Ps.-Cyrillus glossaries are normally dated to Late Antiquity, most likely the sixth century. This dating has not been reconsidered since 1865, when Rudorff examined such evidence as was then available and tentatively suggested the early sixth century. ${ }^{28}$ Loewe stated explicitly that he accepted Rudorff's dating: ${ }^{29}$ later scholars largely avoided mentioning the dating issue directly, but an assumption of a sixth-century date runs through their work. Thus, for example, Laistner suggests that the proto-glossary was composed in a south Italian monastery not founded until the middle of the sixth century, ${ }^{30}$ Goetz wonders whether the use of Festus was direct or indirect, ${ }^{31}$

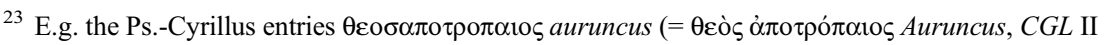

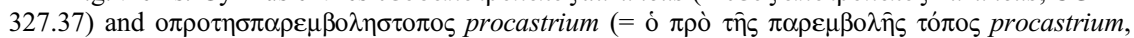
CGL II 385.67) would make much more sense as Latin-Greek entries. See Goetz (n. 9 [1923]), 33 and Loewe (n. 4), 216.

${ }^{24}$ Goetz (n. 9 [1923]), 24-5; Loewe (n. 4), 190-1; Dammann (n. 9), 3-12; H. Rudorff, 'Über die Glossare des Philoxenus und Cyrillus', Philologische und historische Abhandlungen der königlichen Akademie der Wissenschaften zu Berlin (1865), 181-231, at 230.

${ }_{25}$ 'Denique te admoneo, lector, unam rem siquam aliam ex hoc uolumine discas, glossographorum priscorum doctrinam nullo modo in glossariis quae extant ... conseruari. Immo hae glossae collectae sunt ex marginali codicum adnotatione a monachorum magistris satis indoctis adscripta' (W.M. Lindsay, Glossaria Latina II [Paris, 1926], iii). Cf. Dionisotti (n. 5), 220-1.

${ }^{26}$ Goetz (n. 3), 1439; Loewe (n. 4), 190-1; also Dammann (n. 9), 12-16.

${ }^{27}$ Laistner (n. 2), 129; Lindsay (n. 8), 159-60.

${ }^{28}$ Rudorff (n. 24), 228-30.

29 Loewe (n. 4), 182.

${ }^{30}$ Laistner (n. 2), 136; but Goetz, in his review of this volume (n. 2 [1926]), 603, thinks the composition was 'wohl schon etwas früher'.

${ }^{31}$ Goetz (n. 9 [1923]), 31; the idea is that Ps.-Philoxenus' use of Festus took place so long after Festus' own time that Festus' original text might no longer have been available. 
and Lindsay, suggesting that the compilation took place in Italy and speculating about the use of papyrus, cites a sixth-century papyrus glossary as an example of what the glossary might once have looked like and remarks 'The use of papyrus continued in Italy for a fairly long time.' ${ }^{32}$

\section{PAPYRUS FRAGMENTS OF BILINGUAL GLOSSARIES}

Since Rudorff's day the discovery of numerous fragments of ancient bilingual glossaries on papyrus has shed more light on what types of glossaries were in use at different periods and the extent to which the glossaries preserved in medieval manuscripts are related to ancient fragments. ${ }^{33}$ These papyri are one of the reasons why Rudorff's dating continues to be accepted, since they have until now implied that the large bilingual glossaries are indeed products of Late Antiquity. They fall into four groups: glossaries ordered by topic (thirteen examples, including some that probably contained only a single topic), glossaries in alphabetical or alphabetical and grammatical order (five examples plus the newly discovered fragment in P.Vars. 6), ${ }^{34}$ running vocabulary lists for extracts from Virgil (three examples) and glossaries with no discernible ordering principle (three examples).

\subsection{Non-alphabetical glossaries}

The three unordered glossaries range in date from the first century B.c. to the fourth century A.D. and are thus all relatively early. ${ }^{35}$ They show no signs of relationship with any of the glossaries preserved in medieval manuscripts, and they must all have been fairly small, since a glossary with thousands of entries is largely useless if not organized in some fashion. The three running glossaries to Virgil, which all date to the fifth or sixth century A.D., are also unrelated to glossaries surviving via the medieval manuscript tradition and also likely to have been fairly small, since they seem to provide vocabulary for particular passages rather than for entire texts. ${ }^{36}$

${ }^{32}$ Lindsay (n. 8), 163; note also his suggestion (at 161) that the source of the Virgil entries is 'a monastery MS. of Virgil', and his assertion that the ultimate sources of most entries were glosses collected from the margins of manuscripts in monasteries (Lindsay [n. 25], iii).

${ }^{33}$ In the following sections abbreviations of papyrological publications follow the Checklist available at http://www.papyri.info/docs/checklist, and TM refers to the Trismegistos database, available at https://www.trismegistos.org. New editions of all the papyri mentioned will shortly be forthcoming in M.C. Scappaticcio (ed.), Corpus of Latin Texts on Papyrus (Cambridge).

${ }^{34}$ The comparative rarity of alphabetically ordered glossaries may seem surprising, since that order is so prevalent today, but it makes sense in a world where written texts did not normally indicate word division. Today's language students can use an alphabetically ordered dictionary to decipher a text even early in their studies, but ancient learners could not do so until they knew enough vocabulary to work out where the words began and ended. That is why systematic vocabulary building was prioritized in ancient language-learning contexts - and why the glossaries designed to help with such vocabulary building, the ones ordered by topic, were the most common. Cf. J. Debut, 'De l'usage des listes de mots comme fondement de la pédagogie dans l'antiquité', REA 85 (1983), 261-74.

${ }^{35}$ BKT IX 150 (= J. Kramer, Glossaria bilinguia in papyris et membranis reperta [Bonn, 1983], no. $1=T M$ 65514, from the first century B.C.), P.Lond. II 187 (= E. Dickey, The Colloquia of the Hermeneumata Pseudodositheana II [Cambridge, 2015], 284-7 = TM 64454, from the fourth century A.D.), P.Berol. inv. 21860 (= Dickey [this note], 280-3=TM 67628, from the fourth century A.D.).

${ }^{36}$ PSI VII 756 (= M. Fressura, Vergilius Latinograecus: corpus dei manoscritti bilingui dell' Eneide: parte prima [Pisa, 2017], no. 3=TM 62963, from the fifth century A.D.), P.Oxy. 1099 
The thirteen glossaries ordered by topic (known as classified glossaries or capitula), on the other hand, often do show a relationship to the classified glossaries found in medieval manuscripts. These papyri tend to be early, with eleven datable to the first through fourth centuries. ${ }^{37}$ The medieval manuscripts to which they are related all belong to the Hermeneumata Pseudodositheana, a collection of bilingual materials preserved in nine different versions that range in date from the Carolingian period to the Renaissance and are all to some extent interrelated. ${ }^{38}$ Most of the thirteen papyri containing classified glossaries reveal a relationship to the Hermeneumata, or even to a particular Hermeneumata version, by a high percentage of matching word pairs, strings of entries in the same order, and identically phrased section headings. ${ }^{39}$ The glossaries in these papyri are therefore likely to be ancestors of the Hermeneumata classified glossaries surviving in medieval manuscripts, and hence they were probably not larger than the surviving Hermeneumata classified glossaries. These surviving glossaries range in size from a few hundred entries to a few thousand; they are not tiny, but nothing approaching the size of Ps.-Philoxenus. ${ }^{40}$ It is therefore likely that in antiquity none of the classified glossaries was ever anywhere near as large as Ps.-Philoxenus.

\subsection{Alphabetical glossaries}

The five ancient fragments in alphabetical or partially alphabetical order represent the closest parallels to Ps.-Philoxenus. ${ }^{41}$ The earliest of these, P.Oxy. 3452, dates to the

(=Fressura [this note], no. $7=T M 62970$, from the fifth or sixth century A.D.), portions of P.Ness. II 1 (=P.Colt 1 = M.C. Scappaticcio, Papyri Vergilianae [Liège, 2013], no. $6=T M$ 62974, from the sixth century A.D.). Numerous other papyri contain the full text of extracts from Virgil with a running Greek translation in a 'columnar' format that allows them to be used like glossaries; see the corpora edited by Fressura and by Scappaticcio. For similar bilingual papyri of Cicero's Catilinarians, see D. Internullo, 'Cicerone latinogreco: corpus dei papiri bilingui delle Catilinarie di Cicerone', Papyrologica Lupiensia 20-21 (2011-12), 25-150.

${ }^{37}$ P.Oxy. 2660 = TM 63291, P.Oxy. $3315=$ TM 63292, P.Oxy. $5162=$ TM 171907, P.Oxy. $5163=$ $T M$ 171908, all from the first or second century A.D.; P.Lund I $5=\operatorname{Kramer}(\mathrm{n} .35)$, no. $9=$ TM 63532, from the second century A.D.; P.Mich. inv. $2458=\operatorname{Kramer}(\mathrm{n} .35)$, no. $12=T M 63848$, from the second or third century A.D.; P.Oxy. 2660a =TM 64163 and P.Laur. IV 147=TM 27520, both from the third century A.D.; P.Strasb. inv. G $1173=$ J. Kramer, Glossaria bilinguia altera (Munich, 2001), no. $6=T M$ 67947, from the third or fourth century A.D.; P.Fay. 135v descr. $=$ Kramer (n. 35), no. $11=T M 66430$ and PSI inv. $1734=\operatorname{Kramer}$ (n. 35), no. $10=T M 64407$, both from the fourth century A.D.; P.Vindob. inv. L $150=$ Kramer (this note), no. $5=T M 64815$, from the fifth century A.D.; P.Paris 4 bis $=T M$ 65244, from the sixth or seventh century A.D.

38 See Dickey (n. 2), 16-20.

39 For example, compare the section on winds in the Bruxellensia version of the Hermeneumata (CGL III 395.66-396.6) to P.Oxy. 5162 lines 32-42. More details on these relationships are provided in my forthcoming re-editions of the papyri concerned, in Scappaticcio (n. 33).

${ }^{40}$ The classified glossary of the Hermeneumata Leidensia has c.1,300 entries, that of the Amploniana c.700, Monacensia and Einsidlensia c.2,700 each, Montepessulana c.2,900, Stephani c. 1,800, Bruxellensia $c .400$ and Vaticana $c .1,000$.

${ }^{41}$ In this section I have calculated the relationship between different glossaries by means of word pairs, i.e. lemma + gloss. Entries containing multiple glosses are considered not as units but in terms of their component word pairs: for example the papyrus-glossary entry $\pi \alpha \rho \alpha \chi \mu \alpha \zeta \varepsilon 1$ hibernat hiemat (Cologne fragment, line W1) has no exact match in the intact glossaries, but it is counted as two pairs that between them have three matches: in Ps.-Philoxenus hiemat $\pi \alpha \rho \alpha \chi \mu \alpha \zeta \dot{\varepsilon}$ (CGL II 68.40) and hibernat $\pi \alpha \rho \alpha \chi \varepsilon \mu \alpha \zeta_{\zeta} \varepsilon$ (CGL II 68.43), and in the Hermeneumata parachimazi hibernat (CGL III 157.4). This procedure is justified because extra glosses could be added to entries over time: the entry in the papyrus might have started life as one of those in the intact glossaries. When only one language is preserved on the papyrus, I have counted it as matching all the places in the intact glossaries where that Latin or Greek word appears, on the grounds that we simply cannot know 
second century A.D. and is alphabetized by two letters; thus the section for words begin-

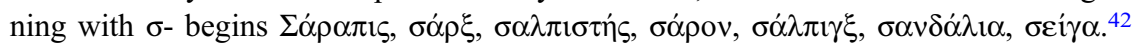
This alphabetization allows one to calculate (by assuming that the percentage of words beginning with particular letter pairs was the same as in the $O L D$ ) that the complete glossary probably had c.1,400 entries. This papyrus shows no signs of relationship to any other known glossaries. ${ }^{43}$

From the third century A.D. come two fragments, P.Sorb. I 8 and P.Sorb. inv. 2069, that are alphabetized by the first letter only; these glossaries simply group together all words beginning with the same letter. ${ }^{44}$ This system makes their original size harder to calculate, but enough survives to make it likely that neither glossary was originally extensive; each may have had fewer than 1,000 entries. ${ }^{45}$ These glossaries are both unrelated to other known glossaries. ${ }^{46}$

From the sixth century A.D. come a pair of fragments, one now in Cologne and the other now in Göttingen, that are believed to have belonged originally to different halves of the same work. ${ }^{47}$ The Cologne fragment, a Greek-Latin glossary, is alphabetized by four or five letters, but the Göttingen one, a Latin-Greek glossary, is arranged first by ending (we have the end of the section for Latin nouns and adjectives in -is and the beginning of the section for ones in -tas), and within each section is alphabetized on the Latin by one or two letters. The original size of the glossary represented by the Cologne fragment was large, perhaps 16,000 entries; the original size of the glossary represented by the Göttingen fragment is harder to calculate but was probably not small. ${ }^{48}$ There has been considerable debate about whether these fragments are related

which (if any) it actually matched. This method therefore may overestimate relationship in the case of poorly preserved papyri.

42 Kramer (n. 37 [2001]), no. $7=T M 63603$.

4385 per cent of its word pairs occur in the $C G L$ glossaries, but this is largely because of the inclusion of words that occur in multiple glossaries rather than because of a relationship to a particular glossary: 77 per cent of the word pairs in this papyrus are shared with Ps.-Cyrillus, 62 per cent with the Hermeneumata and 38 per cent with Ps.-Philoxenus, but at most one of those words is unique

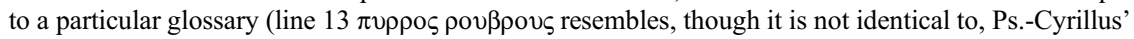
$\pi v \rho \rho o s$ ruseus rubricus rufus at CGL II 426.45). These calculations, based on seven intact entries and six Greek words whose Latin is lost, use the methods described in n. 41 above.

${ }^{44}$ P.Sorb. I $8=$ Kramer (n. 35), no. 3 = TM 64220; P.Sorb. inv. $2069=$ E. Dickey and R. Ferri, 'A new edition of the Latin-Greek glossary on P.Sorb. inv. 2069 (verso)', ZPE 175 (2010), 177-87=TM 64219. Kramer claims that P.Sorb. I 8 is arranged in alphabetical order by the first letter and reverse alphabetical order by the second and third, but this is unlikely; see discussion in the forthcoming re-edition in Scappaticcio (n. 33).

${ }^{45}$ P.Sorb. inv. 2069 was nevertheless a long text, because it provided a lot of information about each entry.

4650 per cent of the word pairs in P.Sorb. I 8 and 22 per cent of those in P.Sorb. inv. 2069 do not occur in any of the intact glossaries; 39 per cent of the pairs in I 8 and 53 per cent of those in 2069 are shared with Ps.-Cyrillus, 33 per cent and 45 per cent with Ps.-Philoxenus, 33 per cent and 37 per cent with the Hermeneumata. Words unique to particular glossaries rarely appear in these papyri: 6 per cent of the word pairs in I 8 and 17 per cent of those in 2069 are unique to Ps.-Cyrillus, 11 per cent and 13 per cent are unique to Ps.-Philoxenus, 0 per cent and 5 per cent are unique to the Hermeneumata. For P.Sorb. inv. 2069 these figures are calculated on the basis of all sixty surviving word pairs; for P.Sorb. I 8, a much smaller fragment, the calculations are based on twelve surviving word pairs and six Latin words whose Greek is lost, using the methods described in n. 41 above.

${ }^{47}$ Folium Wallraffianum (Cologne, Historisches Archiv inv. W* 351) and Fragmenta Helmstadiensia (Göttingen, inv. Diplomatischer Apparat $8 \mathrm{C}+8 \mathrm{D}$ ), which are edited together in Kramer (n. 35), no. 4=TM 65038 .

${ }^{48}$ See Kramer (n. 35), 45-6; Dickey (n. 35), 145 n. 8; R. Ferri, 'I frammenti lessicografici bilingui di Colonia e Gottinga e la tradizione dei dizionari greco-latini nell'antichità', in G. Albanese, 
to surviving glossaries; current thinking is that they are related to Ps.-Cyrillus but only distantly. ${ }^{49}$

Thus far the papyrus glossaries have suggested that until Late Antiquity bilingual lexica were fairly small and completely unrelated to the alphabetical glossaries surviving via the manuscript tradition: the only papyrus fragment so far discussed that might approach Ps.-Philoxenus in size or that might be related to a surviving alphabetical glossary dates to the sixth century. But another alphabetical glossary, only recently discovered, complicates that picture. This papyrus, P.Vindob. inv. L 27, dates to the fourth century A.D. and was previously thought to be a classified glossary; it has recently been reinterpreted as a partly alphabetical glossary like the Göttingen fragment. ${ }^{50}$ It contains Latin neuter nouns and adjectives that begin with $\mathrm{co}$ - and end with -um, with their Greek glosses; the original glossary must have contained at least thirty such entries. Such a scale suggests that the original could have been large. ${ }^{51}$ It also seems to be distantly related to several of the glossaries surviving via the manuscript tradition, though not to Ps.-Philoxenus or to Ps.-Cyrillus. ${ }^{52}$

\section{P.VARS. 6}

\subsection{Evidence for identification and reconstruction}

In 1935 a small papyrus fragment bearing a list of Greek words was published as P.Vars. $6 .^{53}$ The editor, Jerzy (Georgius) Manteuffel, remarked that traces of another column were visible to the left of the Greek words, and those traces were subsequently

C. Ciociola, M. Cortesi and C. Villa (edd.), Il ritorno dei classici nell'umanesimo: Studi in memoria di Gianvito Resta (Florence, 2015), 257-78, at 262-3.

${ }^{49}$ Kramer proposed that they were part of the Celtis version of the Hermeneumata (J. Kramer, 'Lateinisch-griechisches Glossar: Celtis' Abschrift aus einem Papyruskodex', in J.M.S. Cowey and B. Kramer [edd.], Paramone: Editionen und Aufsätze von Mitgliedern des Heidelberger Instituts für Papyrologie zwischen 1982 und 2004 [Munich, 2004], 43-62, at 43-7), but Ferri disproved this (R. Ferri, 'Hermeneumata Celtis: the making of a late-antique bilingual glossary', in id. [ed.], The Latin of Roman Lexicography [Pisa, 2011], 141-69, at 143-6; cf. Dickey [n. 35], 144-8) and argued that they were instead associated with Ps.-Cyrillus (Ferri [n. 48], 270-5). But the relationship cannot be close, for 35 per cent of the word pairs in the Cologne and Göttingen fragments do not occur in the intact glossaries at all, and the ones that do occur are fairly evenly distributed and tend to be found in more than one of those glossaries: 50 per cent of the pairs are shared with Ps.-Cyrillus, 37 per cent with the Hermeneumata glossaries, 32 per cent with Ps.-Philoxenus. The word pairs unique to particular glossaries are poorly represented: only 8 per cent of the words on these fragments are unique to Ps.-Philoxenus, 8 per cent unique to Ps.-Cyrillus, 3 per cent unique to the Hermeneumata. These figures are calculated on the basis of a sample of sixty word pairs, thirty from each fragment; in twenty-nine of these only one language survives.

${ }^{50} T M$ 64528, originally edited by Kramer, e.g. (n. 37 [2001]), no. 4; re-edition with useful discussion by Marco Fressura in N. Carlig, M. de Haro Sanchez, G. Nocchi Macedo and A. Ricciardetto (edd.), Le médecin et le livre: Hommages à Marie-Hélène Marganne (Lecce, 2021), 143-62.

51 Words beginning with $c o$ - make up 5.4 per cent of all Latin words (calculated from the $O L D$ ); therefore, this glossary probably contained more than five hundred neuters ending in -um. When one considers that originally there were probably more than thirty entries beginning with $\mathrm{co}$ - and that neuters in -um are not a large percentage of the Latin language, it becomes likely that the original glossary had more than a few thousand entries.

${ }^{52}$ Fressura (n. 50) suggests a relationship to the Glossae nominum (CGL II 563-97), the Idiomata codicis Harleiani (CGL II 487-506) and the Glossae Servii grammatici (CGL II 507-33).

${ }^{53}$ G. (= J.) Manteuffel, Papyri Varsovienses (Warsaw, 1935), 13=TM 64235. A photograph is available at http://www.papyrology.uw.edu.pl/papyri/pvars6v.htm. 
identified as the ends of Latin words. ${ }^{54}$ Closer investigation reveals a striking correspondence between the text on this papyrus and Ps.-Philoxenus' glossary. Twelve of the Greek words on the papyrus are either completely legible or sufficiently legible

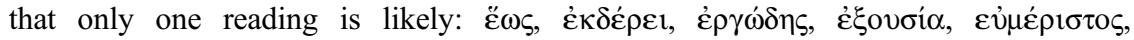

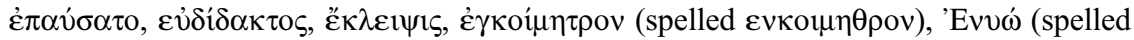

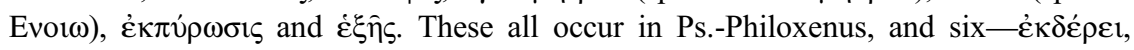

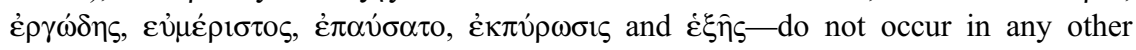
bilingual glossaries. This makes it likely that the missing Latin words should be supplemented from Ps.-Philoxenus.

The P.Vars. glossary must have been alphabetically ordered by the Latin, which was in the first column, and it is clear that in the section covered by this papyrus the Latin words began with $D$-. Of the twelve Greek words just mentioned, eight appear in Ps.-Philoxenus only with (an) equivalent(s) beginning with $D$-: dum, donec and doni-

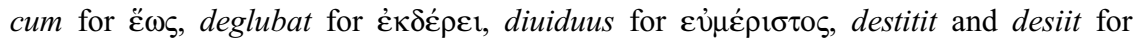

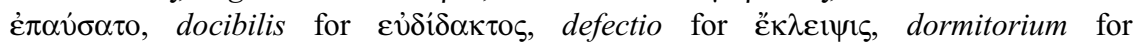

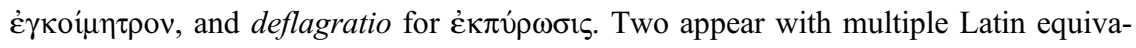
lents including at least one beginning with $D$-: dicio, arbitrium, licentia and potestas for $\dot{\varepsilon} \xi o v \sigma i \alpha$ and deinceps and porro for $\dot{\varepsilon} \xi \hat{\eta} s$. The remaining two Greek words appear in Ps.-Philoxenus only with Latin equivalents that do not begin with $D$-, but they both have an obvious equivalent beginning with $D$ - that also appears in Ps.-Philoxenus with a different Greek gloss: difficilis for દ̇ $\rho \gamma \omega \dot{\delta} \eta \varsigma$ and Duellona for 'Evvó.

These equivalents fit well with the scanty remains of the Latin column on the papyrus. Duellona, dormitorium, deflagratio and diuiduus fit the traces before their respective Greek equivalents, and dicio and desiit are short enough to fit in front of $\dot{\varepsilon} \xi o v \sigma i \alpha$ and $\dot{\varepsilon} \pi \alpha v \dot{\sigma} \alpha \tau$, where short Latin words must have stood. One set of Latin traces allows us

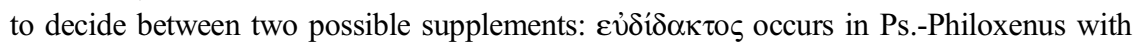
docibilis and in Ps.-Cyrillus with docilis, but the latter is too short to be restored on this papyrus, effectively bringing to seven the number of entries in this papyrus that cannot match any surviving glossary except Ps.-Philoxenus.

In addition to the twelve securely identifiable Greek words, the papyrus also has some whose readings are less certain. Two of these can be read as words occurring in

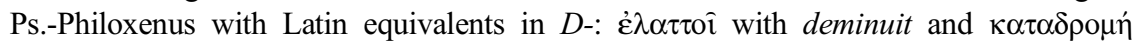
with decursus. One line can be read as containing variants of a word that occurs in

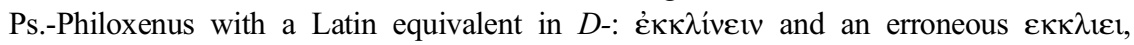
both probably with declinare (which Ps.-Philoxenus pairs with the aorist infinitive $\dot{\varepsilon} \kappa \kappa \lambda \hat{i} v \alpha \mathrm{l})$. One seems to be a misspelling of a word that does not occur in Ps.-Philoxenus but appears in Ps.-Cyrillus with a Latin equivalent in $D$-: عi $\sigma \alpha \gamma \gamma \varepsilon \lambda \varepsilon v i s$ (here apparently spelled with other Greek equivalents). Finally, one cannot easily be read to match any entry in the glossaries. Accordingly the papyrus text can be restored as follows.

\subsection{Text, translation and notes}

1

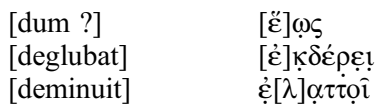

while

he/she peels, strips off skin he/she diminishes/diminished

54 This observation, whose source I have been unable to trace, can be found in the $T M$ entry. 
5 [dicio]

[diuiduu]s

[declinare]

[desiit ?]

[docibi]!̣is

10

[defectio]

[dormit]ọium

[Duell]ọna

[deflagra]tị̣

[deinceps]

15

[decursus ?]

[delator?]

\begin{tabular}{|c|}
\hline 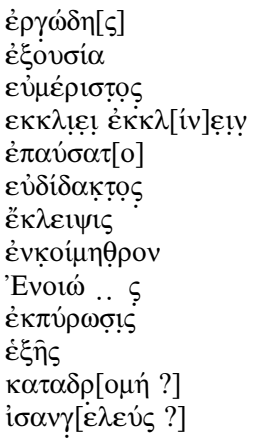 \\
\hline
\end{tabular}

difficult

power

easily divisible

to turn away

he/she ceased

teachable

failing, omission

nightgown

war-goddess

conflagration

one after another

attack

accuser

Notes (references to CGL II are to Ps.-Philoxenus unless otherwise specified):

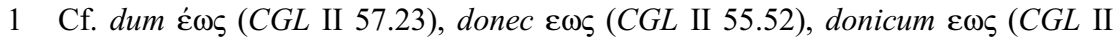
55.53). Any of these might have stood here.

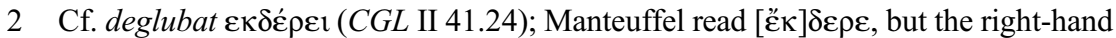
edge of $\kappa$ and the bottom tip of $\imath$ are both visible.

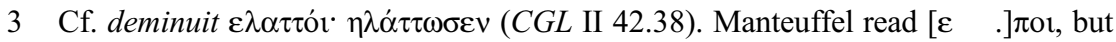
the first intact letter is too wide for $\pi$, and its crossbar extends too far to the right; $\tau \tau$ is much more likely.

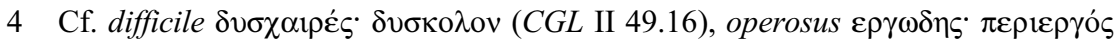

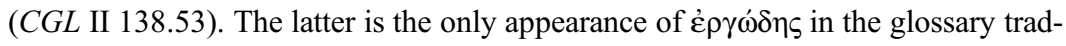
ition, but it does not offer an ideal match: '̇ $\gamma \gamma \omega \dot{\delta} \eta \varsigma$ means 'difficult' (cf. LSJ), while operosus means 'diligent', 'active', 'toilsome', 'busy' and 'ornate' (cf. $O L D$ ). The pair difficilis $\dot{\varepsilon} \rho \gamma \omega \dot{\delta} \eta \varsigma$ is a better match and therefore likely to have been deployed by an ancient lexicographer at some point.

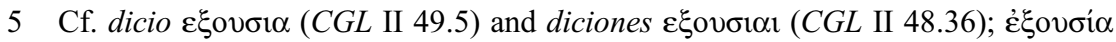
also appears with arbitrium (CGL II 19.4), licentia (CGL II 123.1) and potestas (CGL II 154.54).

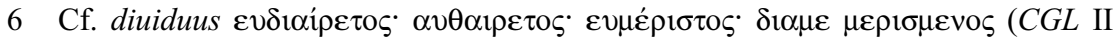

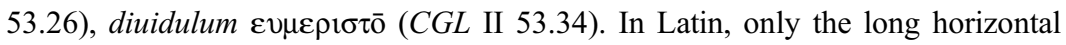
top of $s$ is visible.

7 Cf. declinare $\varepsilon \kappa \kappa \lambda \mathrm{\imath v} \alpha \mathrm{l}$ (CGL 38.44). The traces at the end of the second word are well preserved, but the handwriting at that point is notably more cursive than elsewhere in the papyrus, making their interpretation doubtful. If this reading is right, the scribe wanted to write the present infinitive, accidentally omitted the first $v$, and then stopped and rewrote the whole word (leaving a space after the end of the

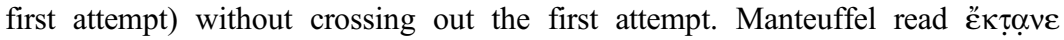
$\dot{\varepsilon} \kappa \kappa \lambda[\eta] \sigma i \alpha$, which is incompatible with the traces of the first word.

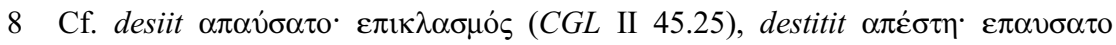
(CGL II 46.9).

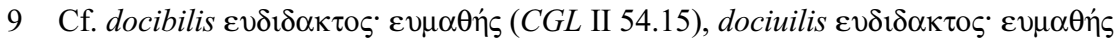

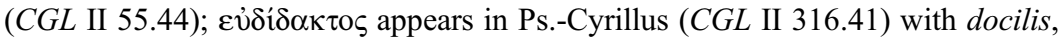
which is too short to fit the Latin traces here. The $L$ is visible only in its long tail stretching below the other letters, and the $I$ in a horizontal top stroke that seems to be a serif. Admittedly, the $I$ in line 11 has no serif, and one could argue that the visible stroke has to come from $S$ or $T$ ( $E$ is implausible since its lower strokes would have also been visible), but in that case the Latin word would have to be severely misspelled: no Latin words end in -SS or -TS. 


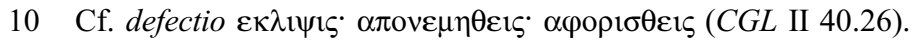

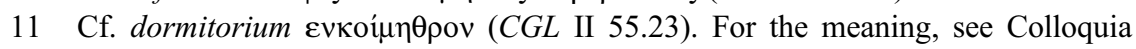

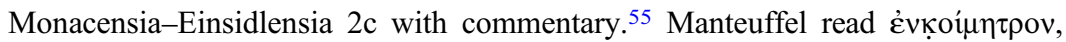
but the vertical is too far to the right for $\tau$.

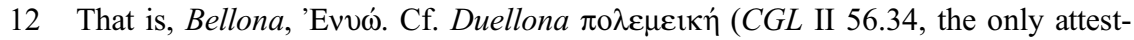

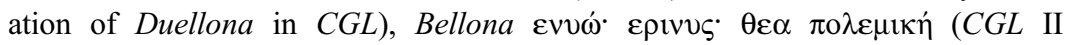
28.52). There is probably a blank space after 'Evotó, and then traces that look

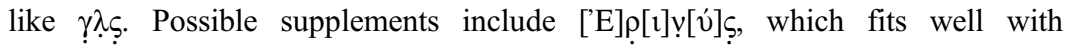
Ps.-Philoxenus but less well with the papyrus (the surface after 'Evot $\dot{\omega}$ does not seem sufficiently damaged that an entire letter could have been lost, and there is inadequate space for $v$ ); Môs, which fits much better with the papyrus but is not in CGL at all (Mô is a Cappadocian name for Enyo [Strabo 12.2.3] and therefore attractive here, but Mô $\varsigma$ would apparently be a genitive); and options that do not seem to make any sense, such as $\pi \hat{\alpha} \varsigma, \gamma \hat{\alpha} \varsigma$ or perhaps 'Iós. Manteuffel read Évouki $[\delta] \mathrm{l}[0] \zeta$, but the $\omega$ is certain.

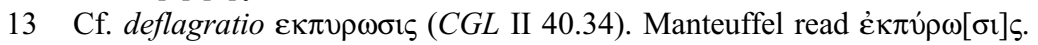

14 Cf. deinceps $\tau \varepsilon \lambda \varepsilon v \tau \alpha \mathrm{lo} \varepsilon \pi \mathrm{\varepsilon} \tau \alpha \varepsilon \xi \eta \varsigma$ (CGL II 38.14 with reading of manuscript $c$ : see apparatus criticus and $C G L$ VI 316, which interprets the Greek as $\tau \varepsilon \lambda \varepsilon v \tau \alpha i o v$,

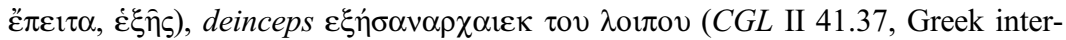

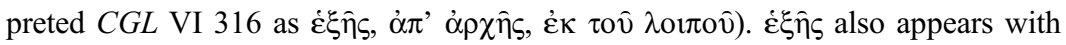
porro (CGL II 153.58).

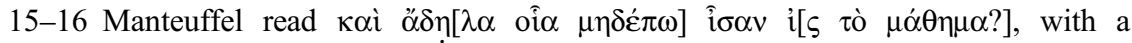
note "i $\sigma \alpha v$ 1. ஸे $\sigma \alpha v$ ?"; I think this is intended to mean 'and obscure things such as were not yet in learning' and that the rationale for restoring continuous text rather than single words here was that these lines do not begin with E- and therefore did not fit with Manteuffel's concept of the text as a list of Greek words beginning with E-. But if the text is in fact Ps.-Philoxenus, there is no reason not to restore individual words here; moreover, the third letter of line 15 is clearly not $\mathrm{i}$ but $\tau$.

15 The sixth letter is probably $\rho$ or $\eta$, and there is only one entry in Ps.-Philoxenus whose Latin begins with $d$ - and whose Greek begins with $\kappa \alpha \tau \alpha \delta \rho-$ or $\kappa \alpha \tau \alpha \delta \eta$-:

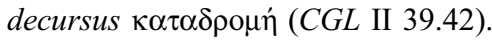

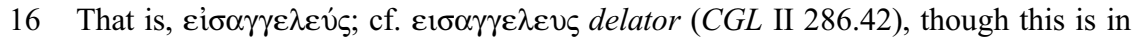
Ps.-Cyrillus rather than in Ps.-Philoxenus. delator does appear in Ps.-Philoxenus,

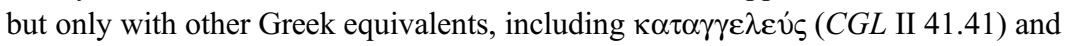

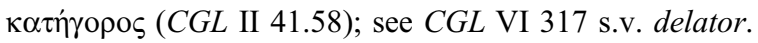

\subsection{Date}

Manteuffel dated P.Vars. 6 to the third century A.D. on the grounds that it is written on the back of a documentary text (P.Vars. 16, a list of names and numbers) which he dated by its handwriting to the late second or early third century. ${ }^{56}$ But all the comparanda he

${ }^{55}$ Dickey (n. 2), 141.

${ }^{56}$ Manteuffel is somewhat inconsistent here; in the introduction to P.Vars. 16 he dates that text to the second/third century, but in the introduction to P.Vars. 6 he dates P.Vars. 16 to the late second century. Likewise in the introduction to P.Vars. 6 he says that P.Vars. 16 is the recto, but in the introduction to P.Vars. 16 he says that P.Vars. 6 is the recto. Inspection of the papyrus shows that P.Vars. 16 is the recto. 
cites for the script of P.Vars. 16 are in fact from the second century, and it looks as though the possibility of a third-century date for that text may have arisen from confusion rather than deliberate decision. ${ }^{57}$ Using a more modern collection of comparanda one arrives at a mid second-century date for P.Vars. $16 .{ }^{58}$

The Greek handwriting of P.Vars. 6 itself is neat and roughly bilinear, partly literary but with a few ligatures and cursive forms. The $\kappa$ is open, shaped similarly to a modern cursive $U$, and the long $\xi$ is made in a single stroke. Good parallels for both the $\kappa$ and the $\xi$, as well as for most of the other letters, can be found on the first hand of P.Oxy. 2192, dated to the end of the second century. P.Tebt. II 318, dated to A.D. 166, is similar in overall appearance but has different shapes for $\kappa$ and $\xi$. A $\kappa$ similar to the one in P.Vars. 6 appears in P.Oxy. 3593, which is dated to A.D. 238-44; many of the other letters on this papyrus also look similar to P.Vars. 6, but there is no $\xi$. P.Ryl. II 176, dated to the beginning of the third century, has both $\kappa$ and $\xi$ similar to P.Vars. 6, though many other letters look different and overall the writing is more cursive.

The Latin script of P.Vars. 6 is difficult to date, because so little of it remains; an analysis of its overall appearance is impossible. Nevertheless, there is one complete example each of $A$ (without crossbar), $I, M, N, R$ (open), $S$ and $V$, and a striking long diagonal tail of an $L$. All these letters except $L$ (which has a similar but shorter tail) are matched in P.Oxy. 894, dated to A.D. 195-6; the long-tailed $L$ can be found in P.Oxy. 1114, dated to A.D. 237, which also shares the forms of $A, I, M, N$ and $V$ (but not $R$ or $S$ ) with P.Vars. 6. The $R, S$ and $N$ (but not $A, I, M$ or $V$ ) are paralleled in P.Mich. III 166, dated to A.D. 128.59

The copying of P.Vars. 6 can thus be located in a narrow window at the end of the second and the beginning of the third century.

\section{THE IMPLICATIONS OF THIS DISCOVERY}

\subsection{The papyrus, Ps.-Philoxenus and the proto-glossary}

This discovery necessitates a re-evaluation of the history of the Ps.-Philoxenus glossary. For one thing, P.Vars. 6 is not at all closely related to Ps.-Cyrillus. ${ }^{60}$ Therefore,

\footnotetext{
57 As comparanda for the recto Manteuffel cites W. Schubart, Papyri Graecae Berolinenses (Bonn, 1911), numbers 25 and 26. Number 25 (BGU I 86=Chr.Mitt. 306) is securely dated to A.D. 155. Number 26 contains two plates; in the introduction to P.Vars. 16 Manteuffel refers to $26^{\mathrm{a}}$ (BGU I 16, dated to A.D. 159/160), but in the introduction to P.Vars. 6 he refers to $26^{\mathrm{b}}(B G U$ III 807 , dated to A.D. 185). The two have distinctly different scripts, and that in $26^{\mathrm{a}}$ is a better match for P.Vars. 16. I therefore suspect that Manteuffel really intended to date P.Vars. 16 to the middle of the second century.

${ }^{58}$ In R. Seider, Paläographie der griechischen Papyri I (Stuttgart, 1967) the best match is number 35 (P.Bad. IV 75b), which is dated to A.D. 147. A photograph of P.Vars. 16 can be found online at http://www.papyrology.uw.edu.pl/papyri/pvars6r.htm.

${ }_{59}$ In R. Seider, Paläographie der lateinischen Papyri I (Stuttgart, 1972) P.Oxy. 894 is number 24, the relevant part of P.Mich. III 166 is number 25b, P.Oxy. 1114 is number 42.

${ }^{60}$ Although line 16 seems to fit Ps.-Cyrillus better than Ps.-Philoxenus, that line is the only example of such a fit, and it is fragmentary. As noted above (section 3.1), six of the legible Greek

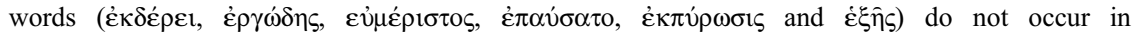

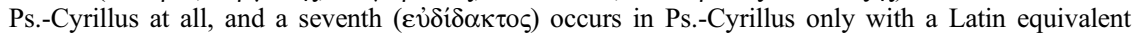
that does not fit the traces on the papyrus. Thus only five of the papyrus' securely reconstructible Greek words occur in Ps.-Cyrillus with the same Latin equivalents as in Ps.-Philoxenus or with others

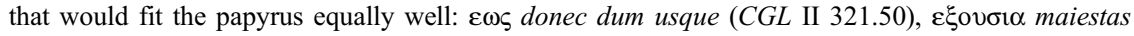


Ps.-Philoxenus and Ps.-Cyrillus, or their sources, were already distinct by c.A.D. 200: those two glossaries cannot have been separately excerpted from a huge proto-glossary in Late Antiquity (cf. 1.3 above). In theory they could have been separately excerpted from the proto-glossary sometime before the late second/early third century, but that would require the existence, in the second century A.D. or earlier, of an enormous bilingual proto-glossary in alphabetical order. This would require an even more radical shift in our understanding of the history of bilingual glossaries than abandoning the idea of the proto-glossary, which therefore now needs to be abandoned. The only concrete evidence in favour of the proto-glossary was the existence of some entries in Ps.-Philoxenus and Ps.-Cyrillus that seemed to come from a common source; a more plausible and economical explanation for that evidence is that the shared source was a small Latin-Greek glossary containing only (or primarily) the shared entries rather than an enormous one containing everything now found in both glossaries. If the proportion of shared entries in the $D$ - section of Ps.-Philoxenus is typical of the work as a whole, there are $c .2,000$ shared entries in total, so the shared source may have been about that length.

Another implication is for the date of Ps.-Philoxenus' glossary. If that glossary is really in this papyrus, then it must have been composed three or four centuries earlier than has long been thought. But before concluding that that is the case, further investigation is needed to determine the exact relationship between the glossary in P.Vars. 6 and the work we know as Ps.-Philoxenus. Though evidently closely related they are not identical, since the entries are in a different order and there are several significant differences in the readings. Three possibilities exist: 1) the glossary in the papyrus basically is Ps.-Philoxenus, but it underwent some changes during the six or seven centuries between the papyrus and our ninth-century manuscript of Ps.-Philoxenus. 2) The glossary in the papyrus was smaller than Ps.-Philoxenus and is only one of a number of different sources that were later combined to make the Ps.-Philoxenus we know. 3) The glossary in the papyrus is not a direct ancestor of our Ps.-Philoxenus at all, but stands in the position of a great-aunt rather than a grandmother; some of the entries that differ from Ps.-Philoxenus were originally as Ps.-Philoxenus has them and have been changed in the papyrus version.

\subsection{Order of entries}

The order of the entries in the papyrus is not only different from that in the manuscripts of Ps.-Philoxenus but also striking in itself, for although the main alphabetization is clearly by first letter of the Latin, there is a secondary alphabetization on the Greek: fourteen entries in a row have glosses beginning with E-. Such secondary alphabetization on the glosses probably arises out of re-alphabetization from Greek-Latin to LatinGreek, a process that periodically occurred with ancient glossaries and has left traces on a number of them. To re-alphabetize a Greek-Latin glossary, an ancient scribe would have taken a fresh roll of papyrus and gone through the entire glossary repeatedly, first copying out all the entries for Latin words beginning with $A$-, then all the entries for Latin words beginning with $B$-, etc. This procedure naturally resulted in a dictionary

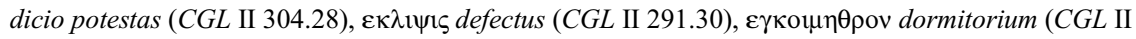
284.3), Evvw Bellona (CGL II 301.5; this one does not fit unless Bellona has been changed from an original Duellona). 
in which, within each section for Latin words beginning with a particular letter, the individual entries were alphabetized on the Greek.

But what about lines 15 and 16, in which the Greek words begin with K- and I- respectively? These cannot simply represent the next section after E-, both because I- should precede $\mathrm{K}$ - and because it is inconceivable that a glossary section large enough to have at least fourteen Greek words beginning with E- had none beginning with $\mathrm{H}$-, $\Theta$-, or Z-. The best explanation for lines 15 and 16 is that they were added after the glossary had been re-alphabetized on the Latin; if someone had then wanted to insert an additional entry for a Latin word beginning with $D$-, he or she would not have felt any need to consider where it fell in the Greek alphabetization but would only have been looking for a place in the $D$ - section with room for another entry, such as the top or bottom of a column. ${ }^{61}$

The Ps.-Philoxenus glossary as preserved in medieval manuscripts also has an unusual order: the Latin words are arranged in Greek alphabetical order, ABGDEHFICLMNOPQRSTV. This Greek ordering applies only to the first letter of each word, however; alphabetization of subsequent letters (almost always the second, usually the third and sometimes the fourth ${ }^{62}$ ) follows the Latin alphabetical order. It therefore seems likely that the glossary's original Greek-speaking author alphabetized entries by only one letter, and a Latin speaker later in the tradition introduced further alphabetization within each section. ${ }^{63}$ If the glossary in the papyrus is Ps.-Philoxenus, therefore, the difference in the order of the entries is probably caused by that further alphabetization, which would have eliminated the secondary alphabetization on the Greek visible in the papyrus.

Therefore, the order of the entries on the papyrus does not indicate that the glossary in the papyrus is not Ps.-Philoxenus. What it does indicate is that the glossary itself is older than the copy in this papyrus: a Greek-Latin glossary was first re-alphabetized and then expanded with additional entries before this copy was made.

\subsection{Duellona}

Duellona, an archaic variant of Bellona, was already obsolete by the first century B.с. ${ }^{64}$ As a lemma in a Latin-Greek glossary an obsolete word is unproblematic, but in a Greek-Latin glossary Duellona would have to be a gloss, and the use of an obsolete word as a gloss is unlikely. Does the inclusion of this word suggest that the glossary goes back to a time when it was not yet obsolete, that is, to the second century B.c.? If the glossary is that old, it is much older than any other language-learning materials of which we have direct or even indirect evidence. Perhaps such an age cannot be completely ruled out, since some second-century B.c. Latin speakers evidently learned Greek, but it is by no means certain. Another possibility is that the glossary could have been re-alphabetized more than once, going through an earlier Latin-Greek phase before the Greek-Latin phase. It might seem unlikely that anyone would go to the effort of re-alphabetizing a work into an order it had previously had, rather than

${ }^{61}$ Both words come at the bottom of a column on this papyrus, but that is probably coincidental since they do not appear to be later additions to the papyrus itself. The Greek word in line 16 seems to be a misspelling of one that should have begun with E-, so for that entry another possibility might be that the Greek was in fact originally written with E- and alphabetized with the other Ewords, and the misspelling arose later.

${ }^{62}$ Alphabetization by four letters occurs e.g. in CGL II 38.27-39.3.

${ }^{63}$ Goetz (n. 9 [1923]), 23-5.

64 Varro, Ling. 5.73 Bellona ab bello nunc, quae Duellona a duello; cf. TLL s.v. Bellona. 
simply using a copy of the older version, but there might have been a good reason to do so. Perhaps the person who did the second re-alphabetization was unaware of the glossary's history and/or did not have access to a copy of the older version, or perhaps the glossary had been expanded since the first re-alphabetization and the later scribe wanted a Latin-Greek version of the newer, larger glossary.

We cannot be sure exactly what happened, but in either case the glossary in the papyrus must have even more of a history than is evident from its ordering alone. It must either have been re-alphabetized twice (with enough of an interval between the two to cause a second re-alphabetization to be plausible) before being expanded, or it must go back to the second century B.c. The glossary must therefore be substantially older than the papyrus copy we have; this means that, instead of being three or four centuries earlier than the assumed date of Ps.-Philoxenus, it is at least four or five centuries earlier.

\subsection{Words from identifiable sources of Ps.-Philoxenus}

The papyrus seems to have contained a number of entries that previous studies of Ps.-Philoxenus have assigned to particular sources. Laistner's edition of Ps.-Philoxenus specifies the sources of many glosses, including for deflagratio Cicero. ${ }^{65}$ If that attribution is correct, at least some of the material that the Ps.-Philoxenus glossary took from literary sources was already in the papyrus glossary. (And given the shorter time frame now available between the composition of the literary texts themselves and their incorporation into the glossary, the intermediate Latin-Latin phase now seems much less likely. ${ }^{66}$ )

The papyrus also contains three entries that Laistner traced to Festus: deglubat, deinceps and Duellona. ${ }^{67}$ These attributions suggest that the Festus material was also already in the papyrus glossary-and they call into question the idea that Festus himself was the source of all the material that Laistner ascribes to him. If the compiler of the glossary had been working in Late Antiquity, Festus would have been a special treasury of material difficult to access in other ways. But someone compiling a bilingual glossary in (or before) the early second century A.D. would have had access to many other sources of rare and archaic Latin vocabulary. ${ }^{68}$ Regardless of whether the actual source of the 'Festus' material is Festus himself or (an)other work(s) of Latin philology or both, however, that source had already been used by the time of the papyrus glossary.

65 Laistner (n. 2), DE 161.

${ }^{66}$ Clearly there was a Latin-Latin source involved at some point, as some Latin-Latin glosses remain in our version of Ps.-Philoxenus. But as noted above (section 1.2) those glosses seem to come primarily from Horace; it is more economical to argue that the Horace material was separately added in a Latin-Latin form than that all the other entries were also originally Latin-Latin and that someone who replaced the Latin glosses with Greek ones systematically skipped the Horace entries.

${ }^{67}$ In Laistner's numeration deglubat (marked 'Fest.?', perhaps because one would have expected Festus to prefer Classical deglubere to deglubare) is DE 206, deinceps (marked 'Fest. 62.7?') is DE 219, Duellona is DU 40; Duellona is marked 'Fest. 30.19?', but that seems to be a typographical error for Fest. 30.14, the Bellona entry. Festus references are to the page and line of Lindsay's Teubner edition.

${ }^{68}$ Some scholars had long suspected that Festus himself was not the source of all the 'Festus' glosses in Ps.-Philoxenus. C. Theander ('Studia glossographica', Eranos 26 [1928], 243-52, at 243-6) pointed out that many of the Plautine entries attributed by Lindsay to Festus either do not appear at all in our versions of Festus or appear only with glosses different from those in Ps.-Philoxenus; Theander argued that at least some of these come instead from Varro. And Goetz's list of Ps.-Philoxenus glosses derived from Festus at CGL I (n. 9), 28-31 is far more modest than Laistner's attributions; it does not include any entries related to P.Vars. 6. 
The papyrus also contains some of the material that Ps.-Philoxenus shares with

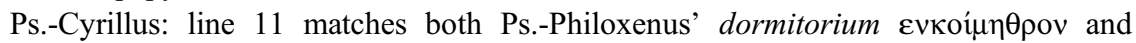
Ps.-Cyrillus' $\varepsilon \gamma \kappa о \mu \eta \theta \rho o v$ dormitorium. ${ }^{69}$ Both words in this entry are extremely rare, so the match is unlikely to be coincidental: this entry was taken from the shared source, which therefore had already been used by the compiler of the papyrus glossary. As observed above (section 4.1), the shared source is likely to have been a Latin-Greek glossary of $c .2,000$ entries.

The rest of the entries on the papyrus cannot easily be assigned to any of these three sources, a fact that implies the existence of additional sources for the papyrus glossary. The overall picture of this glossary that emerges, therefore, is of something similar to Ps.-Philoxenus itself in terms of sources; the papyrus glossary does not look like just one of the sources of Ps.-Philoxenus.

\subsection{Size of the papyrus glossary}

The original size of the papyrus glossary is also crucial to the question of whether it is Ps.-Philoxenus or merely one of the sources of Ps.-Philoxenus. The glossary is written on the back of a document; that position might suggest a short text, but copies of short documents were sometimes kept together on a longer roll, so a long text is not impossible. The preserved part of another Latin-Greek alphabetical glossary, P.Sorb. inv. 2069 , is also on the back of a document, but nevertheless that glossary was clearly much longer than the document itself.

The multiple sources suggest a large glossary. It is unlikely that an individual source was used more than once in the history of the same glossary, so once any source can be identified as having been used by the compiler of the papyrus glossary, it is reasonable to suppose that all the Ps.-Philoxenus entries from that source were already in the papyrus glossary. Therefore, if all the 'Festus' entries really do come from Festus, then those entries must all have been in the papyrus glossary-but, as we have seen, those entries may have several sources, and therefore it is possible that only some were already in the papyrus glossary. The source shared with Ps.-Cyrillus, however, is likely to have been a single source, and therefore it is probable that all the $c .2,000$ entries Ps.-Philoxenus has from that source were already in the papyrus glossary. And those entries formed a relatively small percentage of the whole glossary, since most of the entries in the papyrus are not in Ps.-Cyrillus. Therefore, the glossary in the papyrus must originally have been large; in fact it cannot have been much smaller than the Ps.-Philoxenus glossary as we now have it. It cannot have been just one of a number of sources of Ps.-Philoxenus; it can only have been that glossary or a close relative of similar size and composition.

\section{CONCLUSION}

Because the glossary in P.Vars. 6 is either Ps.-Philoxenus or a close relative of similar size and composition, and is substantially earlier than A.D. 200, the Ps.-Philoxenus glossary must go back at least to the second century A.D. and probably earlier. It is not a

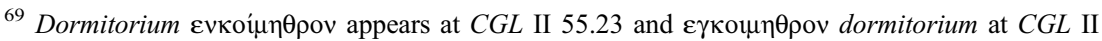
284.3 . 
creation of Late Antiquity but of the Early Empire or perhaps even the Republic. Therefore, large bilingual glossaries in alphabetical order already existed at that early period, and other bilingual glossaries surviving via the medieval manuscript tradition may also be much earlier than previously thought. These glossaries are the product of a long, complex creation process that does not allow for the confident reconstruction of specific sources, but that nevertheless preserves a large body of old lexicographical material in fairly good condition.

University of Reading

ELEANOR DICKEY e.dickey@reading.ac.uk 